\title{
Pathogenic Leishmania spp. detected in lizards from Northwest China using molecular methods
}

\author{
Jun-Rong Zhang ${ }^{1}$, Xian-Guang Guo², Han Chen ${ }^{1}$, Jin-Long Liư ${ }^{2,3}$, Xiong Gong ${ }^{2}$, Da-Li Chen ${ }^{1 *}$ and \\ Jian-Ping Chen ${ }^{1 *}$ (D)
}

\begin{abstract}
Background: Leishmaniosis, a disease caused by pathogenic Leishmania parasites, remains an unresolved health problem in the New World and the Old World. It is well known that lizards can be infected by a subgenus of Leishmania parasites, i.e. Sauroleishmania, which is non-pathogenic to humans. However, evidence suggests that lizards may also harbor pathogenic Leishmania species including the undetermined Leishmania sp., discovered in our previous work. Leishmania DNA in lizard blood can be detected by using molecular methods, such as the polymerase chain reaction (PCR).
\end{abstract}

Results: Three hundred and sixteen lizards, representing 13 species of four genera, were captured for blood samples collection in Northwest China. Two reliable molecular markers (cytochrome $b$ and heat shock protein 70 genes) were used for detection in the lizard blood samples, to confirm a widespread presence of pathogenic Leishmania parasites and the distribution pattern of Leishmania spp. in lizards from Northwest China. The PCR data indicated positive detection rate for Leishmania in all the tested lizards with an overall prevalence of 57.91\% (183/316). Apart from lizard parasites like Leishmania tarentolae and Leishmania sp., several pathogenic Leishmania including L. turanica, L. tropica and L. donovani complex were identified by using phylogenetic analysis. Co-existence of different haplotypes was observed in most Leishmania DNA-positive lizards with an overall rate of $77.6 \%(142 / 183)$. Even mixed infections with different Leishmania species appeared to occur in the lizards with an overall rate of 37.7\% (69/183).

Conclusions: Lizards can harbor pathogenic Leishmania spp. Co-existence of different haplotypes or even species of Leishmania indicates mixed infections in natural lizard host. Lizards may contribute to the spread of Leishmania parasites. The pathogenic Leishmania species detected in lizards from Northwest China may be of great eco-epidemiological importance.

Keywords: Lizard, Leishmania, Pathogenic, Mixed infection, Haplotypes, Northwest China

\section{Background}

With over 6500 species, lizards are a widespread group of squamate reptiles that occur across all continents except Antarctica [1]. Lizards are known reservoirs for numerous parasites, such as kinetoplastea and apicomplexan parasites including coccodea and haematozoea [2-6] and thus play important roles in ecological processes. Several investigations have reported the isolation of a subgenus of

\footnotetext{
* Correspondence: cd11978119@sina.com; jpchen007@163.com 1 Department of Parasitology, West China School of Basic Medical Sciences and Forensic Medicine, Sichuan University, Chengdu 610041, China Full list of author information is available at the end of the article
}

Leishmania from lizards, i.e. Sauroleishmania [7-9]. Currently, it is widely accepted that Leishmania strains from reptiles are non-pathogenic for warm-blooded organisms $[7,8]$; however, doubt rises that lizards may harbor human pathogens, with several reports on amastigotes described within lizard blood cells $[10,11]$. The role of reptiles in the epidemiology of leishmaniosis is still controversial and is far from being completely understood $[7,12]$.

Human leishmaniosis is endemic in 97 countries and territories around the world, and remains a major public health problem. Caused by different species of the genus Leishmania, the condition manifests from self-healing

(c) The Author(s). 2019 Open Access This article is distributed under the terms of the Creative Commons Attribution 4.0 International License (http://creativecommons.org/licenses/by/4.0/), which permits unrestricted use, distribution, and 
cutaneous leishmaniosis (CL) to muco-cutaneous leishmanosis (MCL) and fatal visceral leishmaniosis (VL) [13]. In China, leishmaniosis is still an important public health problem and VL is the main form. Around 1951, 530,000 cases in more than 650 counties were reported. Although leishmaniosis has been eliminated in most areas after powerful national control measures, it remains endemic in the western region of China, especially in Xinjiang Uygur Autonomous Region, Gansu, and Sichuan provinces [14]. According to the epidemiological characteristics, VL is divided into three forms in China: the anthroponotic type (AVL), the zoonotic mountain type (MT-ZVL), and the zoonotic desert type (DT-ZVL) [15]. Four different sand fly species have been verified as vectors: Phlebotomus chinensis, P. longiductus, P. wui, and $P$. alexandri [16]. DT-ZVL is largely distributed in the northwestern region of China where ancient oases and deserts are closely located nearby, no reservoir host has yet been identified [17]. Two recent outbreaks of DT-ZVL, reported in Xinjiang, have called for effective control and prevention in this region [18, 19]. While dogs are recognized as particularly important reservoirs, few dogs and other canids can be found in these areas. Although there are some reports of wild and domestic animals infected with Leishmania [20-22], no reservoir host has been identified in this region.

Recent reports of domestic animals infected with Leishmania in this region suggest that there may be other potential reservoirs. A previous study has established a method of screening lizards for Leishmania infections and it has shown to be of great value for research [23]. In the previous study three species of Leishmania were found to exist in lizards, including two pathogenic Leishmania species, i.e. L. tropica and $L$. donovani. This supports the idea that reptiles should be considered as potential hosts for Leishmania infections [23]. In order to confirm whether there is a widespread presence of more pathogenic Leishmania parasites and to test the pattern of low host specificity of Leishmania spp. in lizards from Northwest China, more reliable molecular markers and samples should be used for detection.

\section{Results}

\section{Lizards sampling and Leishmania detection}

A total of 316 blood samples from lizards representing 13 species were obtained from 31 points in Northwest China (Table 1). The species of lizard, captured in each location, range from one to four. The number of lizards, captured for each species, ranged from six (Trapelus sanguinolentus) to 83 (Phrynocephalus versicolor). Two gene markers were used to genotype the DNA obtained from the blood samples of lizards in this study: Cyt $b$ and HSP70. One hundred and eighty-three samples were observed to be positive for Leishmania DNA by PCR, indicating a high prevalence of Leishmania infection at 57.91\% (95\% CI, 52.47-63.35\%).

As shown in Table 2, all examined species of lizards were found to be positive for Leishmania and the prevalence of Leishmania DNA in different species of lizards was significant different $(P=0.00,<0.05)$. The prevalence of Leishmania infection in Phrynocephalus alpherakii was 90.91\% (95\% CI, 73.92-107.9\%), which was much higher than that in any other species. This was especially significant compared to that in Lacerta agilis, which was $16.67 \%$ (95\% CI, 13.15-46.49\%) $(P=0.02,<0.05)$. The prevalence of Leishmania infection in P. melanurus and $P$. axillaris was $77.78 \%$ (95\% CI, 62.1-93.46\%) and 83.33\% (95\% CI, 62.24-104.42\%), respectively. For P. versicolor, a total of 83 lizards were captured from 12 districts with an infection rate of $72.29 \%$ (95\% CI, 62.66-81.92\%).

The 31 points belong to 15 districts located in six regions and two provinces, where sandflies were reported and DT-ZVL is endemic in these points. As shown in Table 3, infection with Leishmania DNA in lizards from different locations were also significant different $(P=0.00$, $<0.05)$. Absence of Leishmania DNA from lizards in Zhaosu County and Fukang County may be related to the small number of the samples (only one and four lizards, respectively) (Table 3). In Hami City, all the sampling lizards were infected by Leishmania. The prevalence of Leishmania infection in Jinghe County, Yiwu County and Dabancheng district was 88.46\% (95\% CI, 76.18-100.74\%), 76.27\% (95\% CI, 65.41-87.13\%) 78.95\% (95\% CI, 60.6297.28\%), respectively. Fourteen lizards were captured in Qitai County; however, only one was detected as positive for Leishmania DNA.

\section{Phylogenetic analysis}

Sequencing of HSP70 and Cyt $b$ was performed on Leishmania positive samples; the products were approximately $738 \mathrm{bp}$ and $543 \mathrm{bp}$ in length, respectively. Six clones had been sequenced for each positive sample to ensure that distinct sequences could be obtained for all infected Leishmania. All sequences were subjected for BLAST searching in GenBank and shown to be over 98\% identity similar to Leishmania. In total, 195 HSP70 sequences and 299 Cyt $b$ sequences were obtained and deposited in GenBank under accession numbers MH724314-MH724508 and MH724509-MH724807, respectively. Seventy-five HSP70-haplotypes (unique sequences) and 126 Cyt $b$-haplotypes were identified and used to conduct phylogenetic analyses with 22 and 31 reference sequences, respectively, downloaded from GenBank (see Additional files 1, 2 and 3).

Prior to the Bayesian phylogenetic analyses, the most adequate models of nucleotide substitution were selected 
Table 1 Species and numbers of lizards collected in different districts

\begin{tabular}{|c|c|c|c|c|}
\hline District & Site & $\begin{array}{l}\text { Point } \\
\text { number }\end{array}$ & Lizard species & $\begin{array}{l}\text { Number of } \\
\text { lizards }\end{array}$ \\
\hline \multirow[t]{2}{*}{$\begin{array}{l}\text { Bortala Mongolia Autonomous } \\
\text { Canton, Xinjiang Uygur Autonomous Region }\end{array}$} & \multirow[t]{2}{*}{ S1: Jinghe County } & \multirow[t]{2}{*}{ Point 1} & $\begin{array}{l}\text { Phrynocephalus } \\
\text { melanurus }\end{array}$ & 24 \\
\hline & & & Eremias velox & 2 \\
\hline \multirow{17}{*}{$\begin{array}{l}\text { Ili Kazak Autonomous Prefecture, Xinjiang } \\
\text { Uygur Autonomous Region }\end{array}$} & \multirow[t]{2}{*}{ S2: Xinyuan County } & \multirow[t]{2}{*}{ Point 2} & Eremias arguta & 4 \\
\hline & & & Lacerta agilis & 4 \\
\hline & \multirow[t]{3}{*}{ S3: Gongliu County } & Point 3 & Eremias velox & 3 \\
\hline & & Point 4 & Eremias arguta & 16 \\
\hline & & Point 5 & Eremias velox & 11 \\
\hline & \multirow[t]{3}{*}{ S4: Nilke County } & Point 6 & Eremias arguta & 1 \\
\hline & & \multirow[t]{2}{*}{ Point 7} & Eremias arguta & 10 \\
\hline & & & Lacerta agilis & 1 \\
\hline & \multirow[t]{2}{*}{ S5: Tekes County } & \multirow[t]{2}{*}{ Point 8} & Eremias arguta & 4 \\
\hline & & & Lacerta agilis & 1 \\
\hline & S6: Zhaosu County & Point 9 & Lacerta agilis & 1 \\
\hline & \multirow[t]{6}{*}{ S7: Huocheng County } & \multirow[t]{2}{*}{ Point 10} & Eremias velox & 2 \\
\hline & & & Trapelus sanguinolentus & 2 \\
\hline & & \multirow[t]{4}{*}{ Point 11} & Eremias velox & 8 \\
\hline & & & Eremias grammica & 9 \\
\hline & & & Trapelus sanguinolentus & 4 \\
\hline & & & Phrynocephalus alpherakii & 11 \\
\hline \multirow[t]{6}{*}{$\begin{array}{l}\text { Changji hui Autonomous Prefecture, } \\
\text { Xinjiang Uygur Autonomous Region }\end{array}$} & \multirow[t]{2}{*}{ S8: Fukang City } & \multirow[t]{2}{*}{ Point 12} & $\begin{array}{l}\text { Phrynocephalus } \\
\text { melanurus }\end{array}$ & 3 \\
\hline & & & Eremias velox & 1 \\
\hline & \multirow[t]{2}{*}{ S9: Qitai County } & Point 13 & Eremias multiocellata & 10 \\
\hline & & Point 14 & $\begin{array}{l}\text { Phrynocephalus } \\
\text { grumgrzimailoi }\end{array}$ & 4 \\
\hline & \multirow{2}{*}{$\begin{array}{l}\text { S10: Mori Kazakh Autonomous County/ Mori } \\
\text { County }\end{array}$} & \multirow[t]{2}{*}{ Point 15} & Eremias multiocellata & 12 \\
\hline & & & $\begin{array}{l}\text { Phrynocephalus } \\
\text { grumgrzimailoi }\end{array}$ & 36 \\
\hline \multirow{16}{*}{$\begin{array}{l}\text { Hami Prefecture, Xinjiang Uygur } \\
\text { Autonomous Region }\end{array}$} & \multirow{6}{*}{$\begin{array}{l}\text { S11: Barkol Kazakh Autonomous County/ } \\
\text { Barkol County }\end{array}$} & Point 16 & Phrynocephalus versicolor & 8 \\
\hline & & \multirow[t]{2}{*}{ Point 17} & Eremias vermiculata & 9 \\
\hline & & & Phrynocephalus versicolor & 3 \\
\hline & & Point 18 & Phrynocephalus versicolor & 7 \\
\hline & & Point 19 & Phrynocephalus versicolor & 2 \\
\hline & & Point 20 & Phrynocephalus versicolor & 1 \\
\hline & \multirow[t]{6}{*}{ S12: Yiwu County } & Point 21 & Phrynocephalus versicolor & 15 \\
\hline & & \multirow[t]{2}{*}{ Point 22} & Phrynocephalus versicolor & 2 \\
\hline & & & Eremias vermiculata & 3 \\
\hline & & Point 23 & Phrynocephalus versicolor & 18 \\
\hline & & Point 24 & Phrynocephalus versicolor & 1 \\
\hline & & Point 25 & Phrynocephalus versicolor & 20 \\
\hline & \multirow[t]{4}{*}{ S13: Hami City } & Point 26 & Eremias vermiculata & 3 \\
\hline & & & Phrynocephalus versicolor & 3 \\
\hline & & & Phrynocephalus axillaris & 3 \\
\hline & & Point 27 & Phrynocephalus axillaris & 1 \\
\hline
\end{tabular}


Table 1 Species and numbers of lizards collected in different districts (Continued)

\begin{tabular}{|c|c|c|c|c|}
\hline District & Site & $\begin{array}{l}\text { Point } \\
\text { number }\end{array}$ & Lizard species & $\begin{array}{l}\text { Number of } \\
\text { lizards }\end{array}$ \\
\hline \multirow{6}{*}{$\begin{array}{l}\text { Urumqi City, Xinjiang Uygur } \\
\text { Autonomous Region }\end{array}$} & \multirow{6}{*}{ S14: Dabancheng district } & \multirow[t]{2}{*}{ Point 28} & Phrynocephalus versicolor & 3 \\
\hline & & & Phrynocephalus axillaris & 3 \\
\hline & & \multirow[t]{2}{*}{ Point 29} & Eremias velox & 4 \\
\hline & & & Phrynocephalus axillaris & 5 \\
\hline & & \multirow[t]{2}{*}{ Point 30} & Eremias velox & 3 \\
\hline & & & $\begin{array}{l}\text { Phrynocephalus } \\
\text { grumgrzimailoi }\end{array}$ & 7 \\
\hline Jiuquan City, Gansu Province & $\begin{array}{l}\text { S15: Akesai Kazakh Autonomous } \\
\text { County/Akesai County }\end{array}$ & Point 31 & Phrynocephalus vlangalii & 8 \\
\hline
\end{tabular}

by jModelTest: $\mathrm{TrN}+\mathrm{G}$ for HSP70 and $\mathrm{K} 80+\mathrm{G}$ for Cyt $b$, respectively. For both HSP70 and Cyt $b$ dataset, Bayesian inference and ML analyses produced highly congruent topology, with only minor conflicts on very recent nodes. Thus, only the $\mathrm{BI}$ tree with both PP and BS from ML is presented (Figs. 1 and 2). As shown in Fig. 1, haplotypes HHS1-HHS10 were closely related to Leishmania sp. (accession number of KJ667092), and were referred to as Leishmania sp. west China in this study since most of them were found in Western China. Haplotypes HHD11-HHD75 were clustered with $L$. donovani and $L$. infantum, which were identified as $L$. donovani complex. Haplotype HHD42 shared the same sequence with reference sequence HF586393 ( $L$. infantum isolate of MCAN/IL/97/LRC-L720). Similarly, haplotype HHD53 shared the same sequence with reference sequence HF586352 ( $L$. donovani isolate of MHOM/MA/95/CRE72).

As shown in Fig. 2, haplotype HCTO16 shared the same sequence with reference HQ908257 and could be identified clearly as L. tropica. Haplotypes HCT1HCT15 were clustered together with the reference strains of L. turanica and L. gerbilli with high support $(\mathrm{PP}=0.99 ; \mathrm{BP}=83)$. Haplotypes $\mathrm{HCD} 17-\mathrm{HCD} 83$ were clustered with $L$. donovani and $L$. infantum, and were identified as L. donovani complex. Haplotypes HCS84HSC125 were clustered with Leishmania sp. $(\mathrm{PP}=0.8)$, being identified as Leishmania sp. west China. Haplotype

Table 2 Leishmania DNA detection in blood samples from different lizard species

\begin{tabular}{|c|c|c|c|c|c|c|c|c|c|c|c|c|}
\hline \multirow[t]{2}{*}{ Lizard species } & \multirow{2}{*}{$\begin{array}{l}\text { Number } \\
\text { of lizards }\end{array}$} & \multirow{2}{*}{$\begin{array}{l}\text { Number } \\
\text { of positive } \\
\text { lizards }\end{array}$} & \multirow{2}{*}{ Prevalence } & \multirow[t]{2}{*}{$95 \% \mathrm{Cl}$} & \multicolumn{8}{|c|}{ Number of positive lizards (Infected by) } \\
\hline & & & & & LS & LD & $\mathrm{LT}$ & $\begin{array}{l}\mathrm{LS}+ \\
\mathrm{LD}\end{array}$ & $\begin{array}{l}\mathrm{LS}+ \\
\mathrm{LT}\end{array}$ & $\begin{array}{l}\mathrm{LT}+ \\
\mathrm{LD}\end{array}$ & $\begin{array}{l}\mathrm{LT}+\mathrm{LS}+ \\
\mathrm{LD}\end{array}$ & $\begin{array}{l}\mathrm{LTR}+\mathrm{LS}+ \\
\mathrm{LD}\end{array}$ \\
\hline Phrynocephalus melalurus & 27 & 21 & $77.78 \%$ & $62.10-93.46 \%$ & 21 & 0 & 0 & 9 & - & - & - & 1 \\
\hline Eremias velox & 34 & 16 & $47.06 \%$ & $30.28-63.84 \%$ & 8 & 11 & 4 & 3 & 3 & 2 & 1 & - \\
\hline Eremias arguta & 36 & 20 & $55.56 \%$ & $39.33-71.79 \%$ & 10 & 10 & 1 & 1 & - & - & - & - \\
\hline Lacerta agilis & 6 & 1 & $16.67 \%$ & $\begin{array}{l}-13.15- \\
46.49 \%\end{array}$ & 1 & 1 & 0 & 1 & - & - & - & - \\
\hline Trapelus sanguinolentus & 6 & 2 & $33.33 \%$ & $-4.39-71.05 \%$ & 1 & 2 & 0 & 1 & - & - & - & - \\
\hline Eremias grammica & 9 & 3 & $33.33 \%$ & $\begin{array}{l}2.53 \%-- \\
64.13 \%\end{array}$ & 0 & 3 & 0 & - & - & - & - & - \\
\hline Phrynocephalus alpherakii & 11 & 10 & $90.91 \%$ & $\begin{array}{l}73.92- \\
107.90 \%\end{array}$ & 4 & 10 & 0 & 4 & - & - & - & - \\
\hline Eremias multiocellata & 22 & 10 & $45.45 \%$ & $24.64-66.26 \%$ & 2 & 10 & 0 & 2 & - & - & - & - \\
\hline $\begin{array}{l}\text { Phrynocephalus } \\
\text { grumgrzimailoi }\end{array}$ & 47 & 13 & $27.66 \%$ & $14.87-40.45 \%$ & 3 & 12 & 2 & 2 & 1 & 1 & - & - \\
\hline Phrynocephalus versicolor & 83 & 62 & $72.29 \%$ & $62.66-81.92 \%$ & 31 & 53 & 12 & 23 & 9 & 6 & 4 & - \\
\hline Eremias vermiculata & 15 & 10 & $66.67 \%$ & $42.81-90.53 \%$ & 3 & 10 & 0 & 3 & - & - & - & - \\
\hline Phrynocephalus axillaris & 12 & 10 & $83.33 \%$ & $\begin{array}{l}62.24- \\
104.42 \%\end{array}$ & 5 & 9 & 1 & 5 & - & - & - & - \\
\hline Phrynocephalus vlangalii & 8 & 5 & $62.5 \%$ & $28.95-96.05 \%$ & 3 & 5 & 2 & 3 & 2 & 2 & 2 & - \\
\hline Total & 316 & 183 & $57.91 \%$ & $52.47-63.35 \%$ & 92 & 145 & 22 & 57 & 15 & 11 & 7 & 1 \\
\hline
\end{tabular}

LS Leishmania sp., LT Leishmania turanica, LD Leishmania donovani complex, LTR Leishmania tropica 
Table 3 Leishmania DNA detection in lizards from different geographical districts

\begin{tabular}{|c|c|c|c|c|c|c|c|c|c|c|c|c|}
\hline \multirow[t]{2}{*}{ Districts } & \multirow{2}{*}{$\begin{array}{l}\text { Number } \\
\text { of lizards }\end{array}$} & \multirow{2}{*}{$\begin{array}{l}\text { Number } \\
\text { of positive } \\
\text { lizards }\end{array}$} & \multirow[t]{2}{*}{ Prevalence } & \multirow[t]{2}{*}{$95 \% \mathrm{Cl}$} & \multicolumn{8}{|c|}{ Number of positive lizards (Infected by) } \\
\hline & & & & & LS & LD & LT & $L S+L D$ & $L S+L T$ & $L T+L D$ & $\mathrm{LT}+\mathrm{LS}+\mathrm{LD}$ & $L T R+L S+L D$ \\
\hline Jinghe County (S1) & 26 & 23 & $88.46 \%$ & $76.18-100.74 \%$ & 23 & 9 & 1 & 9 & 1 & - & - & 1 \\
\hline Xinyuan County (S2) & 8 & 4 & $50 \%$ & $15.35-84.65 \%$ & 3 & 1 & 0 & - & - & - & - & - \\
\hline Gongliu County (S3) & 30 & 14 & $46.67 \%$ & $28.82-64.52 \%$ & 6 & 9 & 1 & 1 & 1 & - & - & - \\
\hline Nilke County (S4) & 12 & 8 & $66.67 \%$ & 40.00-93.34\% & 4 & 5 & 0 & 1 & 0 & - & - & - \\
\hline Tekes County (S5) & 5 & 1 & $20 \%$ & $-15.06-55.06 \%$ & 0 & 0 & 1 & - & - & - & - & - \\
\hline Zhaosu County (S6) & 1 & 0 & 0 & 0 & 0 & 0 & 0 & - & - & - & - & - \\
\hline Huocheng County (S7) & 36 & 17 & $47.22 \%$ & $30.91-63.53 \%$ & 5 & 17 & 0 & 5 & - & - & - & - \\
\hline Fukang County (S8) & 4 & 0 & 0 & 0 & 0 & 0 & 0 & - & - & - & - & - \\
\hline Qitai County (S9) & 14 & 1 & $7.14 \%$ & $-6.35-20.63 \%$ & 0 & 1 & 0 & - & - & - & - & - \\
\hline Mori County(S10) & 48 & 16 & $33.33 \%$ & $19.99-46.67 \%$ & 4 & 16 & 0 & 4 & - & - & - & - \\
\hline Barkol County (S11) & 30 & 18 & $60 \%$ & $42.47-77.53 \%$ & 1 & 18 & 1 & 1 & - & 1 & - & - \\
\hline Yiwu County (S12) & 59 & 45 & $76.27 \%$ & $65.41-87.13 \%$ & 27 & 36 & 11 & 19 & 9 & 5 & 4 & - \\
\hline Hami City (S13) & 16 & 16 & $100 \%$ & $100-100 \%$ & 9 & 16 & 0 & 9 & - & - & - & - \\
\hline Dabancheng district (S14) & 19 & 15 & $78.95 \%$ & $60.62-97.28 \%$ & 7 & 12 & 5 & 5 & 2 & 3 & 1 & - \\
\hline Akesai County (S15) & 8 & 5 & $62.5 \%$ & $28.95-96.05 \%$ & 3 & 5 & 2 & 3 & 2 & 2 & 2 & - \\
\hline Total & 316 & 183 & $57.91 \%$ & $52.47-63.35 \%$ & 92 & 145 & 22 & 57 & 15 & 11 & 7 & 1 \\
\hline
\end{tabular}

LS Leishmania sp., LT Leishmania turanica, LD Leishmania donovani complex, LTR Leishmania tropica

HCT8 shared the same sequence with reference AB434675 (L. turanica MRHO/SU/80/CLONE3720); haplotype HCS126 shared the same sequence with M10126 (L. tarentolae).

Multiple haplotypes were found to be present in many lizards. As shown in Fig. 3, haplotypes HHS2, HHD41, HHD42 and HHD69 were present in 20, 29, 22 and 20 lizards from various districts and species, respectively. A total of 18 HSP70-haplotypes were present in at least two lizards (see Additional file 1). Similarly, haplotypes HCT8, HCD77 and HCS92 were present in 15, 69 and 67 lizards from various districts and species, respectively. A total of 19 Cyt $b$-haplotypes were present in at least two lizards (see Additional file 2).

A total of 47/183 PCR positive samples for Leishmania were amplified and sequenced successfully by both Cyt $b$ and HSP70 markers (Additional files 1 and 2). In this study, L. donovani complex DNA was most frequently observed in lizards compared to other Leishmania species.

\section{Discussion}

Leishmaniosis is still endemic in Northwest China. The reservoir for leishmaniosis, however, has puzzled researchers for over half a century. Several wild mammals in this area have been suspected, such as the wood mouse (Apodemus sylvaticus), midday gerbil (Meriones meridianus), and Yarkand hare (Lepus yarkandensis); however, attempts in detecting Leishmania parasites in these mammals have failed [20]. Positive Leishmania
DNA was detected by PCR in blood samples from livestock (sheep, goat, cattle, donkey) in this area [20]. Yet the prevalence was less than $31 \%$ without more evidence accompanied with, such as the presence of the same parasite in reservoirs and humans, geographical distribution overlapped with vectors and so on [24], which is insufficient to support a reservoir role for these parasites.

The fact that reptiles can harbor Leishmania parasites is not unexpected to us. In the early 1970s, Belova noted that 21 species (including Eremias velox) from six lizard families may carry Leishmania promastigotes [7]. Subsequently, in 1982 Guan and his colleagues identified Leishmania amastigotes in lizard samples (Teratoscincus przewalskii) from Northwest China [25]. However, few Leishmania parasites from lizard have been virtually identified and categorized on species level. It is widely accepted that Leishmania parasites from reptiles are nonpathogenic to humans. Intriguingly, the role of reptiles in the epidemiology of Leishmania has yet to be determined. Various lizard species are known natural residents in Xinjiang, China, including lizards from Lacertidae (e.g. E. velox and E. multiocellata) and Agamidae (e.g. P. axillaris, P. grumgrzimailoi) [26]. Based on these facts, it is reasonable to assume that desert lizards in Northwest China may play a role in the epidemiology of leishmaniosis.

In our previous work, DNA of L. donovani, L. tropica and Leishmania $s p$. west China (the previous two species were known as human pathogen) were detected from lizards captured in Xinjiang [23]; the prevalence of 


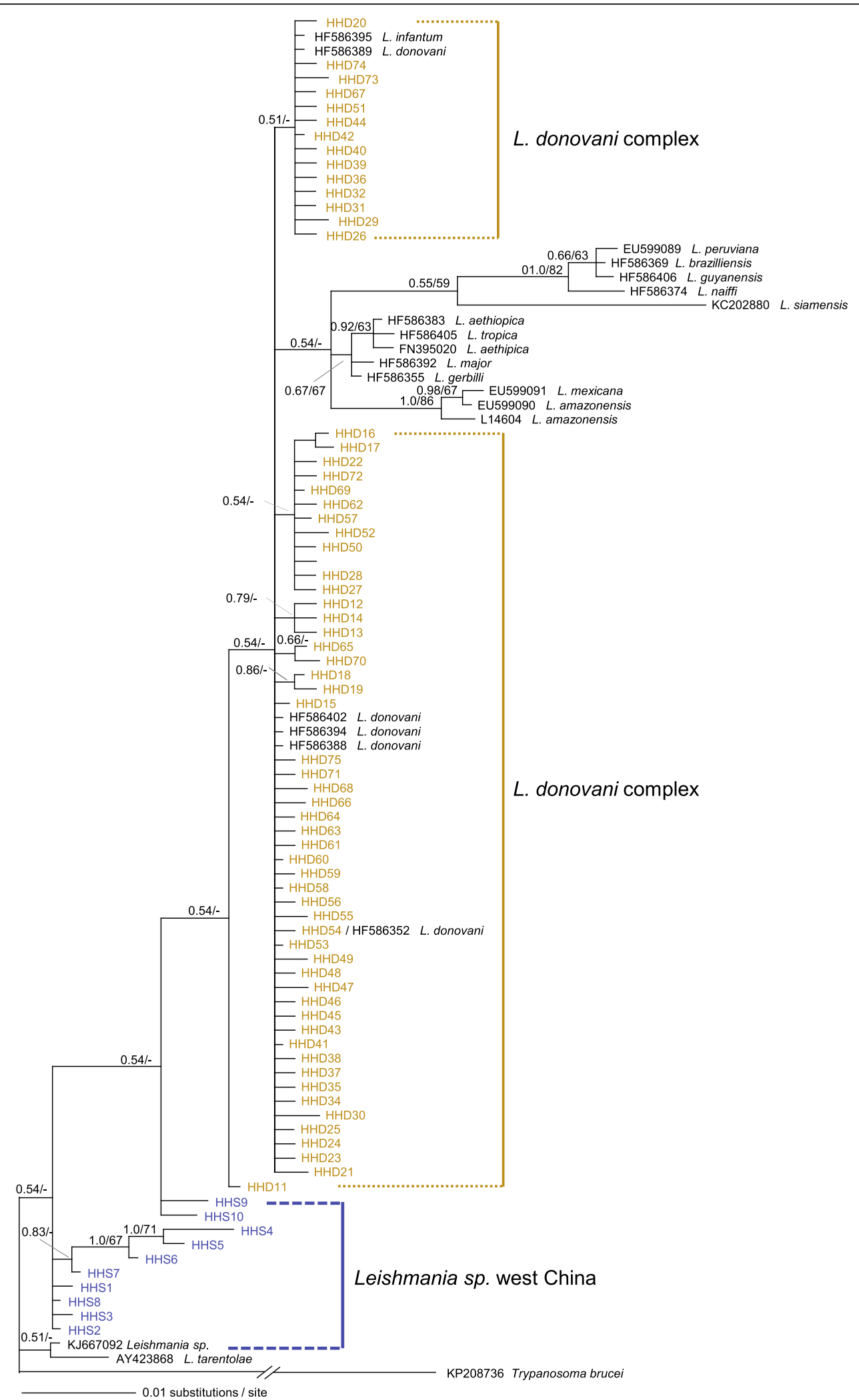

Fig. 1 (See legend on next page.) 
(See figure on previous page.)

Fig. 1 HSP70 gene majority-rule consensus tree inferred from Bayesian inference by using MrBayes v.3.2, associations with less than 0.5 posterior probability were collapsed. Bayesian posterior probabilities and maximum likelihood bootstrap values are shown. Dashes represent nodes with non-parametric bootstrap support lower than $50 \%$ or represent nodes not existed. Texts in colors are used to highlight haplotypes that were obtained in this study

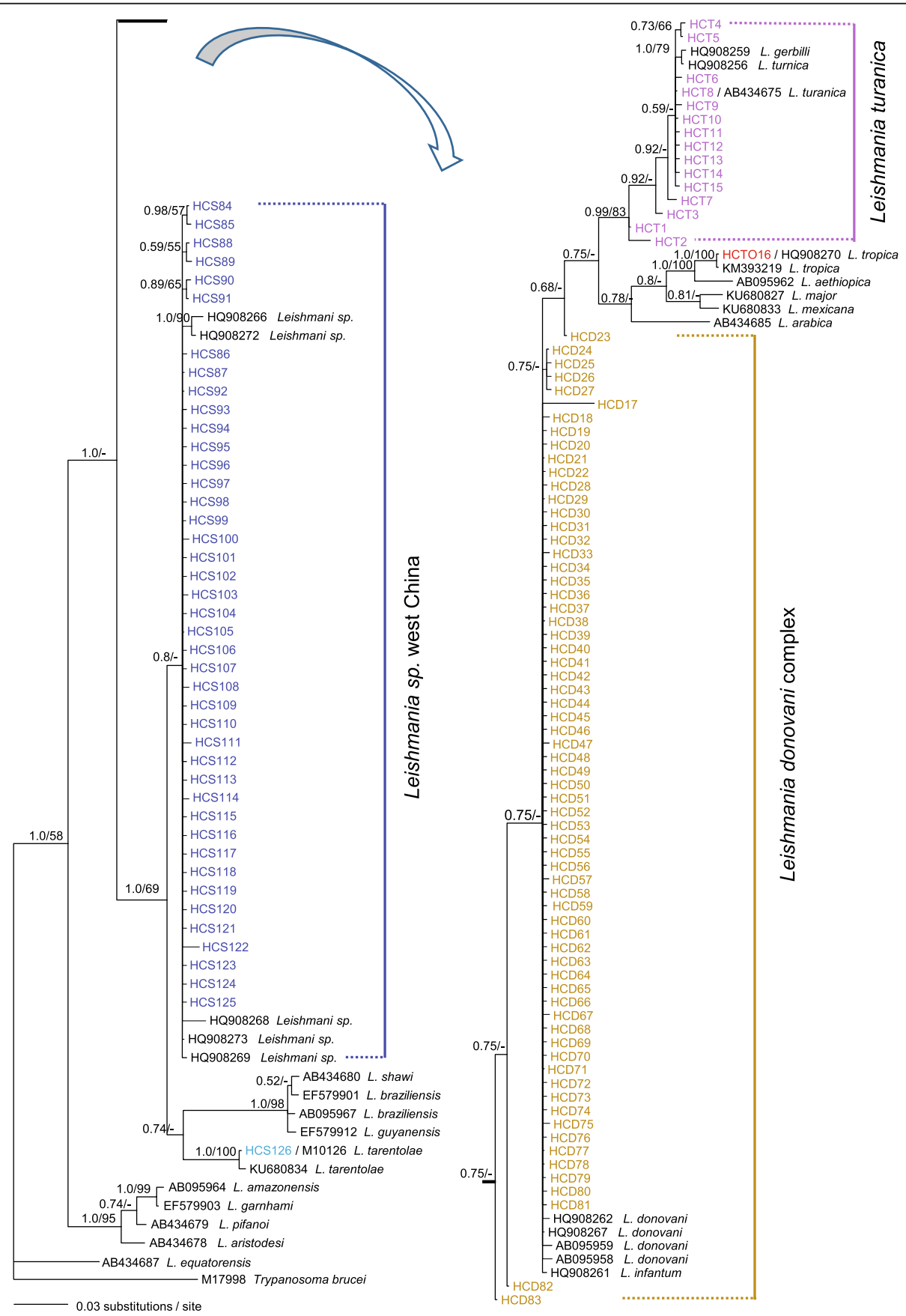

Fig. 2 Cyt $b$ gene majority-rule consensus tree inferred from Bayesian inference by using MrBayes v.3.2, associations with less than 0.5 posterior probability were collapsed. Bayesian posterior probabilities and maximum likelihood bootstrap values are shown. Dashes represent nodes with non-parametric bootstrap support lower than $50 \%$ or represent nodes not existed. Texts in colors are used to highlight haplotypes that were obtained in this study 


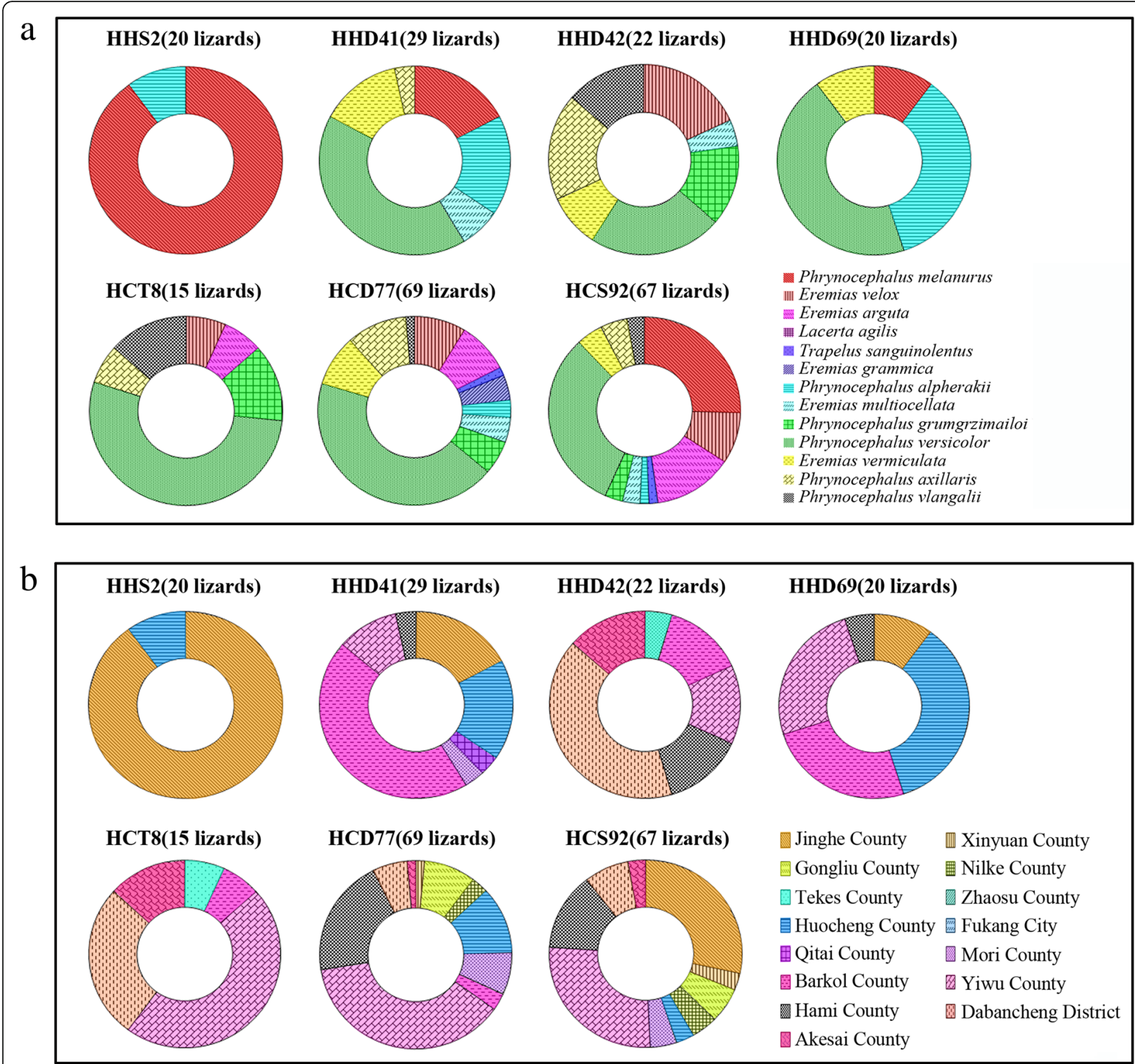

Fig. 3 Common haplotypes obtained in this study. Different filled patterns represent the corresponding host affiliation (a) or geographical origin (b) from which the haplotype was sampled

Leishmania DNA was: E. vermiculata (22/34), Eremias v. roborowskii (14/25), E. multiocellata (6/6), P. axillaris (10/15), and Tenuidactylus elongates (1/1). In this study, 183 out of 316 lizards were detected to be positive for Leishmania DNA by PCR and various pathogenic Leishmania sequences were obtained. The frequency of zoonotic Leishmania spp. in lizard hosts is also presented. Nine additional species were involved in this study, and they appeared to be positive for Leishmania DNA. The prevalence of infection in different species of lizards is significant different $(P<0.05)$. Notably, the prevalence of Leishmania DNA was $90.91 \%$ (10/11) in P. alpherakii, much higher than in other reptiles $(P<0.05)$. However, it is not conclusively known that $P$. alpherakii is the preferential species harboring Leishmania, considering the fact that all specimens of $P$. alpherakii were captured from the same location. Compared to E. velox (47.06\%), the prevalence of Leishmania DNA in $P$. versicolor $(72.29 \%)$ is much higher $(P<0.05)$; this indicates that the difference of the prevalence may be related to hostspecific preference of lizards, while both of them were collected from eight points.

Most regions in Xinjiang are arid deserts without sufficient water, along with various temperatures ranging from $-20^{\circ} \mathrm{C}$ to $40^{\circ} \mathrm{C}$ in summer. Small amounts of wild mammals here are observed in comparison to reptiles. 
Herpetological surveys revealed that arid-adapted lizards are widely distributed in Xinjiang and inhabited in ancient oases, deserts reclaimed by settlers for agricultural development and even around the counties [26]. No evidence has indicated the particular habitats present for the lizards yet. Although temperature is one of the environmental variables shaping the evolution and biology of reptiles, lizards could adjust their body temperature physiologically or through behavioral activity [27]. The preferred temperature and mean value may shift in different species of lizards [28]. This may be related to the difference in the ability of lizards to harbor parasites; no published data, however, support this speculation. Besides, ecology of the transmit vectors on the seasonal distributions and diets of the lizards should also be investigated to understand the specific role of different lizard hosts.

All lizards in this study were captured from localities in or around the endemic foci of DZ-MCL [29-31], where the vector species Phlebotomus longiductus, $P$. wui, $P$. alexandri, and $P$. mongolensis are endemic (shown in Fig. 4) [16, 32]. In present study, DNA of four species of Leishmania was detected in the lizards, i.e. $L$. turanica, L. tropica, L. donovani complex and Leishmania sp. west China. While Leishmania sp., belonging to Sauroleishmania (which is referred to as "lizard Leishmania"), allocated to the same cluster with L. tarentolae, is not beyond expectation. The other three species are known as the pathogenic Leishmania.

A total of 145 lizards (out of 183 Leishmania DNA positive lizards) were detected positive for $L$. donovani complex. It is widely known that $L$. donovani is the causative parasite for fatal visceral leishmaniosis (VL) in this region. From 2006 to 2012, 667 sporadic infantile VL cases, caused by $L$. donovani and $L$. infantum, were reported in Xinjiang [33]; several cases were in or close to our sampling sites.

Leishmania turanica, a well-known human pathogen transmitted by P. mongolensis, was also detected in this study. The species had been discovered in gerbils from Qitai (S8) and Fukang counties (S9) [34]. Human leishmaniosis, caused by this species with $P$. mongolensis as the transmitting vector, had also been reported in this area $[34,35]$. It is assumed that there is a complete life cycle for L. turanica in this region with lizards serving as reservoir hosts.

Leishmania tropica is a protozoa causing anthroponotic cutaneous leishmaniosis as well as visceral leishmaniosis, and is transmitted by the vector of Phlebotomus sergenti. Only one lizard ( $P$. melanurus from Jinhe County, with voucher number Guo4108, see Additional file 1) was detected to have positive DNA of $L$. tropica in present study. The positive detection rate for $L$. tropica was much lower than that in a previous study [23], which had the highest one (16/34) in Eremias vermiculata from the Turpan Depression. Fewer lizards detected to be positive for L. tropica may be related to the different foci where lizards were captured. Meanwhile, different PCR protocols should also be considered into consideration.

Mixed infections of Leishmania parasites are not uncommon in natural hosts from natural environments [36]. Consistent with a previous study [23], 77.6\% (142/ 183) (95\% CI, 71.55-83.64\%) of lizards tested in this study were positive for at least two different haplotypes, and $37.7 \%$ (69/183) (95\% CI, 30.68-44.73\%) were positive for haplotypes of two Leishmania species, and $4.37 \%$ (8/183) (95\% CI, 1.41-7.33\%) were positive for haplotypes of three Leishmania species. The co-existence of different haplotypes or even species may indicate mixed infections. 18.41\% (37/201) of the haplotypes were found in more than two lizards, and seven (HCT8, HCD77, HCS92, HHS2, HHD41, HHD42, HHD69) were found in more than fifteen lizards (Fig. 3). The shared haplotypes could be considered as common ancestry that is transmitted by vectors among lizards. These results also agree well with the notion of low host specificity of Leishmania in lizards [23], being similar to that observed in some other lizard parasites. For example, a recent study revealed that there is limited host specificity and no clear relation to the geographical distribution of Hepatozoon parasites in lizards from North Africa [37].

Interestingly, a large number of haplotypes, either based on HSP70 or Cyt $b$ gene sequences, were clustered into a unique group. This group genetically diverged from any well-known pathogenic Leishmanias species. Instead, these haplotypes were clustered with nonpathogenic $L$. tarentolae in the phylogenetic tree inferred from Cyt $b$ gene sequences, which is consistent with previous studies based on COII [38], Cyt $b$ [39], 18S rRNA and 7SL RNA [40]. However, the DNA sequences analyzed in the previous studies were amplified from Sergentomyia minuta [41], canine leishmaniosis cases [42], and human leishmaniosis cases [43]. It is hypothesized that this undescribed Leishmania species may be a neglected pathogenic species or an optimum hybrid with genetic recombination of natural Leishmania spp. Unfortunately, the pathogenic role of this Leishmania $s p$. west China cannot be established until it is strictly confirmed according to Koch's postulates. Meanwhile, further studies will endeavor to recover this Leishmania $s p$. west China from reptiles, which will be crucial for testing such a hypothesis.

Moreover, more evidences are needed to support the conclusion that lizards could serve as a potential reservoir for leishmaniosis, such as the presence of the same parasite in lizards, sandflies and humans, the maintains of parasites in skin lesions and blood at densities high enough to infect vectors and so on. Further studies on the attempt to 


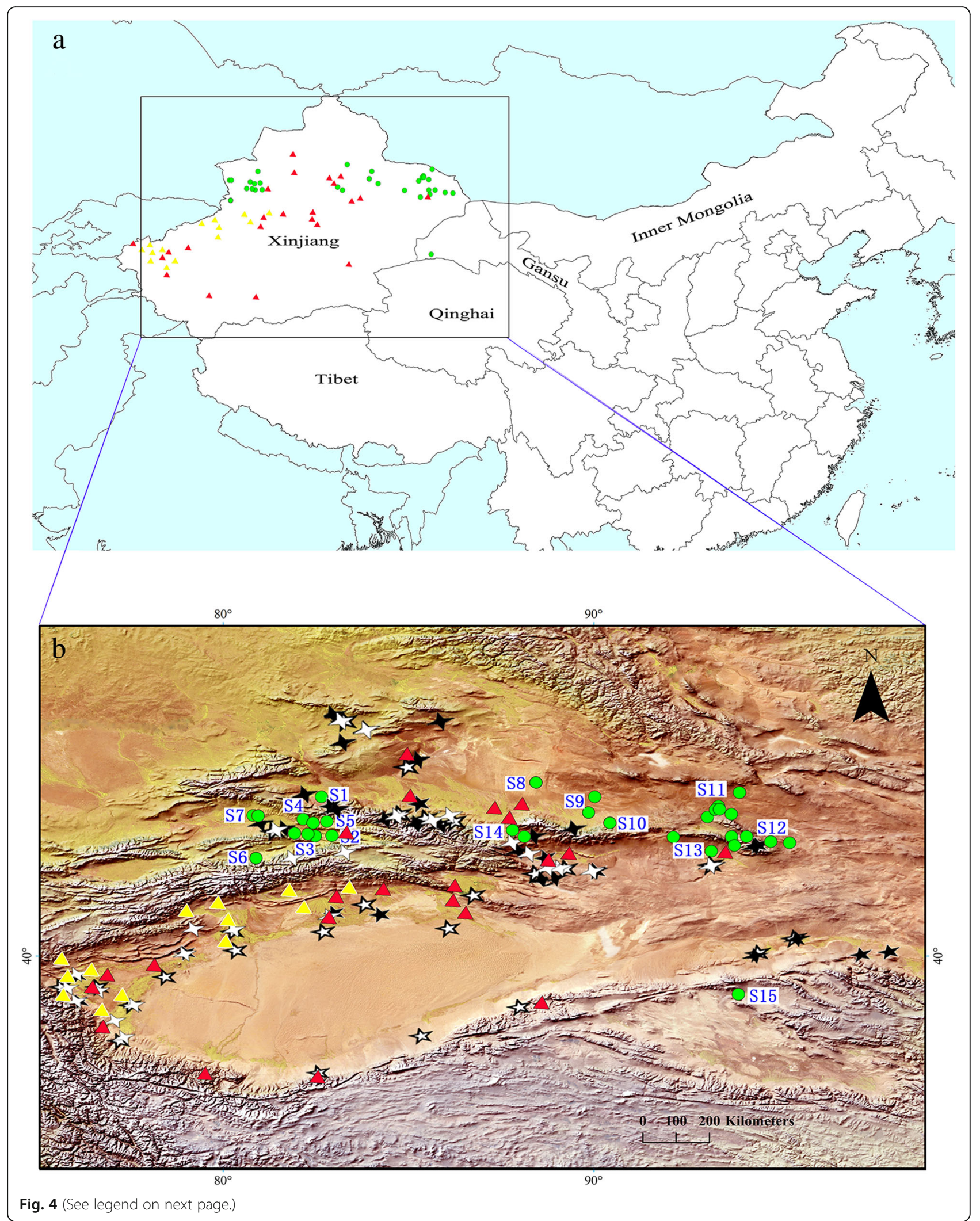


(See figure on previous page.)

Fig. 4 Sampling points of desert lizards in Northwest China, along with the current foci of endemicity of leishmaniosis. The above (a) shows the study area, sampling sites, and foci; the below (b) highlights the topography, sites numbers, and sandfly distribution pattern. Thirty one green solid circles ( ) represent the points where lizards were captured in this study. The site numbers S1-S15 correspond to those in Table 1. Red solid triangles ( $)$ represent desert-type zoonotic visceral leishmaniosis (DT-ZVL) endemic foci. Yellow solid triangles ( ) represent anthroponotic type visceral leishmaniosis (AVL) endemic foci. Distribution of epidemic foci was collected and drawn according to the data published [15, 29-31]. Black and

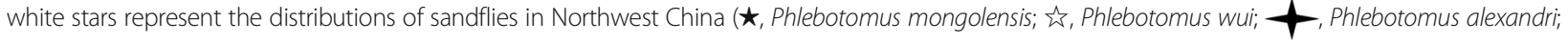
, Phlebotomus longiductus), which were drawn according to the references [16, 32]. The image depicted in this figure is our own

isolate and culture parasites from the lizards and successful complete xenodiagnoses are also necessary.

\section{Conclusions}

In this study we detected and identified Leishmania DNA in infected lizards. The results show a high prevalence of Leishmania in lizards including Leishmania sp. west China, L. turanica, L. tarentolae, L. donovani complex, and L. tropica. The pathogenic Leishmania species and commonly shared sequences in lizard species, from different locations, lend support to the potential reservoir role of lizards for human leishmaniosis. This study helps to understand the spread of epidemic leishmaniosis in Northwest China.

\section{Methods}

\section{Ethics approval and consent to participate}

All the procedures followed protocols approved by medical ethics committee of Sichuan University (No. K2018056) and were carried out under the National Guidelines for Experimental Animal Welfare (MOST of People's Republic of China, 2006). We obtained permits to capture and use the lizards in this study from local legislation.

\section{Study area}

In this study, lizards were captured alive by hand from July to August in 2015 from 31 sites in Northwest China where DT-ZVL is endemic (Fig. 4). This area is characteristic of arid deserts with an average altitude ranging from 400 to $2100 \mathrm{~m}$ above sea level. There are several known endemic foci of desert-type zoonotic visceral leishmaniosis (DT-ZVL) in or close to this area [15, 2931]. All lizards were identified via morphological determination following the classification system of Zhao et al. [44]. The lizards were first anaesthetized with an intraperitoneal injection of $20 \mathrm{mg} / \mathrm{ml}$ of sodium pentobarbital. Then, blood samples were collected from the postorbital sinus directly in the freshly anaesthetized lizards using a heparinized glass capillary tube. After blood collection, all lizards were euthanized with an overdose of sodium pentobarbital delivered by intraperitoneal injection. Voucher specimens were fixed in $75 \%$ ethanol, and are deposited in the herpetological collection of
Chengdu Institute of Biology, Chinese Academy of Sciences.

\section{DNA preparation, amplification, cloning and sequencing}

Total genomic DNA was extracted from blood samples using a commercial DNA extraction kit (TianGen Blood DNA Kit) according to the manufacturer's protocol. Two sets of primers were used to detect Leishmania infections. The primers used to amplify Cyt $b$ gene were L (5'GTTACCATGTACAATGA TGTC-3') and R (5'AATTGTATATTATGATTTGTTTATTGTAG- 3') [45]. The amplification of HSP70 gene was accomplished using primers L (5'-GACAACCGCCTCGTCAGGTTC-3') and R (5'-GCAGATCGAGGTGACGTTCGAC-3') [46]. The PCRs were conducted following previously published methods $[45,46]$. Briefly, a total of $50 \mu \mathrm{L}$ reaction volume was prepared, consisting of dNTPs, MgSO4, buffer and super fidelity enzyme, KOD (TOYOBO Bio-Technology Co., Ltd.); all components were mixed according to the manufacturer's protocol. The PCR protocols for amplification were: $94{ }^{\circ} \mathrm{C}$ for $2 \mathrm{~min}$ followed by 40 cycles of $94{ }^{\circ} \mathrm{C}$ for $30 \mathrm{~s}, 55^{\circ} \mathrm{C}$ for $30 \mathrm{~s}(\mathrm{Cyt} b)$ or $57^{\circ} \mathrm{C}$ for $30 \mathrm{~s}$ (HSP70) and $72^{\circ} \mathrm{C}$ for $1 \mathrm{~min}$, followed by a final extension step at $72{ }^{\circ} \mathrm{C}$ for $10 \mathrm{~min}$. For each reaction, double distilled water was used as a negative control and DNA from Leishmania strain $\mathrm{MHOM} / \mathrm{CN} / 90 / \mathrm{SC} 10 \mathrm{H} 2$ was used as a positive control. The purified PCR products were cloned into pGEM-T vector (Promega, USA) after purification. The ligated vectors were transformed into Escherichia coli DH5 $\alpha$ competent cells, and the recombined plasmids were screened using the blue-white colony selection system. Suspected positive colonies were sequenced with the universal primers M13 on an ABI 3730 automated sequencer (Applied Biosystems, Inc.) at Tsingke Biological Technology Co., Ltd. (Chengdu, China).

\section{Phylogenetic analysis}

Reference sequences were retrieved from GenBank. For HSP70 gene, 22 sequences from Leishmania strains were downloaded; 31 sequences were downloaded for Cyt $b$ gene (see Additional file 3). Sequences from each gene were aligned using Clustal X v1.83 [47]. Distinct sequence types (haplotypes) were defined using DAMBE v5 [48]. 
Phylogenetic relationships among haplotypes were generated by Bayesian inference (BI) with MrBayes v3.2 [49]. Prior to BI analyses, we selected the optimal nucleotide substitution model using jModeltest v2.1.1 [50] under the Bayesian information criterion (BIC) for the dataset of HSP70 and Cyt $b$, respectively. Two independent runs were carried out with four Monte Carlo Markov chains (MCMCs) for $2 \times 10^{7}$ generations with parameters and topologies sampled every 1000 generations. Convergence of the runs was assessed by the standard deviation of split frequencies $(<0.01)$. A $50 \%$ majority-rule consensus tree and posterior probability (PP) of clades were assessed by combining the sampled trees from the two independent runs after a $25 \%$ burn-in phase. Trypanosoma brucei was chosen as outgroup to root the tree, which was visualized using FigTree v1.4.3 [51]. To test the accuracy with which phylogeny could be inferred using the sequence data, the Bayesian approach was compared with the maximum likelihood (ML) method implemented using RAxML v8.2.4 [52] under the model of GTRGAMMA with 100 replicates with a complete random starting tree. For ML trees, node support was assessed by bootstrapping for 1000 replications.

\section{Statistical analyses}

The relationships between the lizards' geographical variables, host specific variable and the infecting Leishmania species were analyzed using the Excel (Office 2016) and IBM SPSS Statistic (version 21.0). The 95\% confidence interval to proportion $(\mathrm{CI})$ was calculated as: upper limit of confidence interval, $\mathrm{P}+1.96 * \operatorname{SQTR}(\mathrm{p}(1-\mathrm{p}) / \mathrm{n})$; lower limit of confidence interval, P-1.96* $\operatorname{SQTR}(\mathrm{p}(1-\mathrm{p}) / \mathrm{n})$. A Chi square test performed to demonstrate the relationships between species of Leishmania and specific characteristics. $P$ value $<0.05$ was established to determine statistical significance.

\section{Supplementary information}

Supplementary information accompanies this paper at https://doi.org/10. 1186/s12917-019-2174-4

Additional file 1. List of lizard samples, origin, detected Leishmania spp., and GenBank accession number for HSP70.

Additional file 2. List of lizard samples, origin, detected Leishmania spp., and GenBank accession numbers for Cyt $b$.

Additional file 3. List of other strains and sequences with accession numbers retrieved from GenBank.

\section{Abbreviations}

AVL: Anthroponotic type of visceral leishmaniosis; BI: Bayesian inference; BIC: Bayesian information criterion; BS: Bootstrap support; Cl: Confidence interval; CL: Cutaneous leishmaniosis; Cyt b: Cytochrome b; DT-ZVL: Zoonotic desert type of visceral leishmaniosis; HSP70: heat shock protein 70; MCL: Muco-cutaneous leishmaniosis; MCMCs: Monte Carlo Markov chains; ML: Maximum likelihood; MT-ZVL: Zoonotic mountain type of visceral leishmaniosis; PCR: Polymerase chain reaction; PP: Posterior probability; VL: Visceral leishmaniosis

\section{Acknowledgements}

We are grateful to two anonymous reviewers whose critical review and insightful suggestions have helped to improve the clarity and focus of the manuscript.

\section{Authors' contributions}

JPC and DLC conceived and supervised the study. JRZ performed the experiments and drafted the manuscript. XGG, JLL, DLC and XG collected the samples. DLC and $X G G$ were in charge of field work coordination to ensure that the project was implemented properly. XGG and HC collected and analyzed the data with assistance of JLL. XGG, JLL and DLC were involved in manuscript revision. JPC and DLC reviewed the manuscript. All authors read and approved the final manuscript.

\section{Funding}

This work was supported by the National Natural Science Foundations of China (31572240, 31872959, 31672270). The funders had no role in study design, data collection, analysis, the decision to publish, or the preparation of the manuscript.

\section{Availability of data and materials}

The sequences generated in the study are available in the GenBank repository under accession numbers MH724314-MH724807.

\section{Ethics approval and consent to participate}

The use of animals and experimental protocols in this study were approved by Medical Ethics Committee of Sichuan University and carried out under the National Guidelines for Experimental Animal Welfare. Permits were obtained to capture and use the lizards in this study from local legislation.

Consent for publication

Not applicable.

\section{Competing interests}

The authors declare that they have no competing interests.

\section{Author details}

${ }^{1}$ Department of Parasitology, West China School of Basic Medical Sciences and Forensic Medicine, Sichuan University, Chengdu 610041, China. ${ }^{2}$ Chengdu Institute of Biology, Chinese Academy of Sciences, Chengdu 610041, China. ${ }^{3}$ University of Chinese Academy of Sciences, Beijing 100039, China.

Received: 21 March 2019 Accepted: 11 November 2019 Published online: 09 December 2019

\section{References}

1. Uetz P, Freed P, Hošek J. The reptile database. http://www.reptile-database. org. Accessed 1 Mar 2019.

2. Ayala SC. Checklist, host index, and annotated bibliography of Plasmodium from reptiles. J Protozool. 1978;25:87-100.

3. Schall JJ, Marghoob AB. Prevalence of a malarial parasite over time and space: Plasmodium mexicanum in its vertebrate host, the western fence lizard Sceloporus occidentalis. J Anim Ecol. 1995;64:177-85.

4. Telford SR Jr. A review of trypanosomes of gekkonid lizards, including the description of five new species. Syst Parasitol. 1995;31:37-52.

5. Sloboda M, Kamler M, Bulantová J, Votýpka J, Modrý D. A new species of Hepatozoon (Apicomplexa: Adeleorina) from Python regius (Serpentes: Pythonidae) and its experimental transmission by a mosquito vector. J Parasitol. 2007;93:1189-98.

6. Halla U, Korbel R, Mutschmann F, Rinder M. Blood parasites in reptiles imported to Germany. Parasitol Res. 2014;113:4587-99.

7. Belova EM. Reptiles and their importance in the epidemiology of leishmaniasis. Bull World Health Organ. 1971;44:553-60.

8. Tuon FF, Neto VA, Amato VS. Leishmania: origin, evolution and future since the Precambrian. FEMS Immunol Med Microbiol. 2008;54:158-66.

9. Wenyon DM. Observations on the intestinal protozoa of three Egyptian lizards, with a note on a cell-invading fungus. Parasitology. 1921;12:133-40. 
10. Wilson V, Southgate B. Lizard Leishmania. In: Lumsden W, Evans D, editors. Biology of Kinetoplastida. New York: Academic; 1979. p. 242-68.

11. Simpson L, Holtz G. The status of Leishmania tarentolae/Trypanosoma platydactyli. Parasitol Today. 1988;4:115-8.

12. Telford SR Jr. The Kinetoplastid hemoflagellates of reptiles. In: Kreier JP, editor. Parasitic protozoa, vol. 10. New York: Academic; 1995. p. 161-223.

13. Murray HW, Berman JD, Davies CR, Saravia NG. Advances in leishmaniasis. Lancet. 2005;366:1561-77.

14. Zhao S, Li Z, Zhou S, Zheng C, Ma H. Epidemiological feature of visceral leishmaniasis in China, 2004-2012. Iran J Public Health. 2015;44:51-9.

15. Lun ZR, Wu MS, Chen YF, Wang JY, Zhou XN, Liao LF, et al. Visceral leishmaniasis in China: an endemic disease under control. Clin Microbiol Rev. 2015:28:987-1004.

16. Guan LR, Zhou ZB, Jin CF, Fu Q, Chai JJ. Phlebotomine sand flies (Diptera: Psychodidae) transmitting visceral leishmaniasis and their geographical distribution in China: a review. Infect Dis Poverty. 2016:5:15.

17. Yan CY, Ai SJ, Kai S. Epidemiological analysis on kala-azar cases during 1990-2014 in kasha prefecture, Xinjiang, China. Int J Med Parasit Dis. 2015; 42:276-9 [Article in Chinese].

18. Osman $Y$, Tong SX, Hou YY. Investigation on epidemic outbreak of visceral leishmaniasis in Jiashi County, Xinjiang in 2008. Bull Dis Control Prev. 2012; 27:1-5, 27 [Article in Chinese].

19. Osman Y, Simayi A, Keyumu K, Ablimit M, Ji F, Hou YY, et al. Investigation on the outbreak of visceral leishmaniasis in 2014 in Jiashi County of Xinjiang. Chin J Parasitol Parasit Dis. 2015;33:357-61 [Article in Chinese].

20. Gao CH, Wang JY, Zhang S, Yang YT, Wang Y. Survey of wild and domestic mammals for infection with Leishmania infantum following an outbreak of desert zoonotic visceral leishmaniasis in Jiashi, People's Republic of China. PLoS One. 2015;10:e0132493.

21. Zhao EM, Chai JJ, Li BS, Li JS, Yi MM, Jiao LE. Epidemiologic survey of kalaazar in Bachu reclamation area, Xinjiang. J Xinjiang Med College. 1985;8: 259-62 [Article in Chinese].

22. Hou YY, Zuo XP, Jiang W. The effects of different doses of Leishmania infantum on the experimental infection of Lagurus lagurus. Endem Dis Bull. 1999:14:74-6 [Article in Chinese].

23. Zhang JR, Guo XG, Liu JL, Zhou TH, Gong X, Chen DL, et al. Molecular detection, identification and phylogenetic inference of Leishmania spp. in some desert lizards from Northwest China by using internal transcribed spacer 1 (ITS1) sequences. Acta Trop. 2016;162:83-94

24. Chaves LF, Hernandez MJ, Dobson AP, Pascual M. Sources and sinks: revisiting the criteria for identifying reservoirs for American cutaneous leishmaniasis. Trends Parasitol. 2007;23:311-6.

25. Guan LR, Jin CF, Xu YX, Cao HX, Yu JG, Liu PZ, et al. Studies on Leishmania in big gerbils and lizards and its sandfly vectors in Ejin Banner, Inner Mongolia Autonomous Region. Acta Acad Med Sin. 1982;4:261-5 [Article in Chinese].

26. Shi L, Yang J, Hou MZ, Zhao H, Dong BJ, Xiong JL, et al. Herpetological surveys of Xinjiang Uygur Autonomous Region. Sichuan J Zool. 2007:4:8128 [Article in Chinese].

27. Stevenson RD. The relative importance of behavioral and physiological adjustments controlling body temperature in terrestrial ectotherms. Am Nat. 1985;126:362-86.

28. Herczeg G, Herrero A, Saarikivi J, Gonda A, Jäntti M, Merilä J. Experimental support for the cost-benefit model of lizard thermoregulation: the effects of predation risk and food supply. Oecologia. 2008;155:1-10.

29. Osman $Y$, Hou YY. Retrospective analysis of prevalence of visceral leishmaniasis in Xinjiang from 2005-2010. Bull Dis Control Prev. 2011;26:3-6 [Article in Chinese].

30. Chai JJ, Zuo XP, Zhang S. The desert type kala-azar in Xinjiang, China. Endem Dis Bull. 1997:4:27-32 [Article in Chinese].

31. Mmtym $\mathrm{Y}$, Zhang HH, Zhang S, Ruiziguli ZMH, Abdwyt S. Epidemic analysis of kala-azar in Xinjiang Uygur Autonomous Region from 2004 to 2014. Bull Dis Control Prev. 2015;30:3-6 [Article in Chinese].

32. Zhang LM, Leng YJ. Eighty-year research of phlebotomine sandflies (Diptera: Psychodidae) in China (1915-1995). II. Phlebotomine vectors of leishmaniasis in China. Parasite. 1997:4:299-306.

33. Fu Q, Li SZ, Wu WP, Hou YY, Zhang S, Feng Y, et al. Endemic characteristics of infantile visceral leishmaniasis in the People's Republic of China. Parasit Vectors. 2013;6:143.

34. Xu YX, Guan LR, Bao YF. Discovery and study of Leishmania turanica for the second time. Chin J Parasitol Parasit Dis. 1996;14:153 [Article in Chinese].
35. Bordbar A, Parvizi P. High infection frequency, low diversity of Leishmania major and first detection of Leishmania turanica in human in northern Iran. Acta Trop. 2014;133:69-72.

36. Ferreira Ede C, Cruz I, Cañavate C, de Melo LA, Pereira AA, Madeira FA. Mixed infection of Leishmania infantum and Leishmania braziliensis in rodents from endemic urban area of the New World. BMC Vet Res. 2015;11:71.

37. Maia JP, Harris DJ, Perera A. Molecular survey of Hepatozoon species in lizards from North Africa. J Parasitol. 2011;97:513-7.

38. Cao DP, Guo XG, Chen DL, Chen JP. Species delimitation and phylogenetic relationships of Chinese Leishmania isolates reexamined using kinetoplast cytochrome oxidase II gene sequences. Parasitol Res. 2011;109:163-73.

39. Yang BB, Chen DL, Chen JP, Liao L, Hu XS, Xu JN. Analysis of kinetoplast cytochrome $b$ gene of 16 Leishmania isolates from different foci of China: different species of Leishmania in China and their phylogenetic inference. Parasit Vectors. 2013;6:32.

40. Guan W, Cao DP, Sun K, Xu JN, Zhang JR, Chen DL, et al. Phylogenetic analysis of Chinese Leishmania isolates based on mall subunit ribosomal RNA (SSU rRNA) and 7 spliced leader RNA (7SL RNA). Acta Parasitol. 2012;57: 101-13.

41. Maia C, Parreira R, Cristóvão JM, Freitas FB, Afonso MO, Campino L. Molecular detection of Leishmania DNA and identification of blood meals in wild caught phlebotomine sand flies (Diptera: Psychodidae) from southern Portugal. Parasit Vectors. 2015:8:173.

42. Sun K, Guan W, Zhang JG, Wang YJ, Tian Y, Liao L, et al. Prevalence of canine leishmaniasis in Beichuan County, Sichuan, China and phylogenetic evidence for an undescribed Leishmania sp. in China based on 7SL RNA. Parasit Vectors. 2012;5:75

43. Hu XS, Yang WT, Lu HG, Yan HP, Chen JP, Ma Y, et al. Sequencing a specific kinetoplast DNA fragment of Leishmania donovani for polymerase chain reaction amplification in diagnosis of leishmaniasis in bone marrow and blood samples. J Parasitol. 2000;84:822-6.

44. Zhao EM, Zhao KT, Zhou KY. Fauna Sinica, Reptilia. Squamata: Lacertilia, vol. 2. Beijing: Science Press; 1999. [Book in Chinese]

45. Luyo-Acero GE, Uezato H, Oshiro M, Takei K, Kariya K, Katakura K, et al. Sequence variation of the cytochrome $b$ gene of various human infecting members of the genus Leishmania and their phylogeny. Parasitology. 2004; 128:483-91.

46. Montalvo AM, Fraga J, Maes I, Dujardin JC, Van der Auwera G. Three new sensitive and specific heat-shock protein 70 PCRs for global Leishmania species identification. Eur J Clin Microbiol Infect Dis. 2012;31:1453-61.

47. Thompson JD, Gibson TJ, Plewniak F, Jeanmougin F, Higgins DG. The CLUSTAL_X windows interface: flexible strategies for multiple sequence alignment aided by quality analysis tools. Nucleic Acids Res. 1997;25:4876-82

48. Xia X. DAMBE5: a comprehensive software package for data analysis in molecular biology and evolution. Mol Biol Evol. 2013;30:1720-8.

49. Ronquist F, Teslenko M, van der Mark P, Ayres DL, Darling A, Höhna S, et al. MrBayes 3.2: efficient Bayesian phylogenetic inference and model choice across a large model space. Syst Biol. 2012;61:539-42.

50. Darriba D, Taboada GL, Doallo R, Posada D. jModelTest 2: more models, new heuristics and parallel computing. Nat Methods. 2012;9:772.

51. Rambaut A. FigTree, version 1.4.3 for Windows. Computer program and documentation distributed by the author. http://tree.bio.ed.ac.uk/software/ figtree/. Accessed 1 Mar 2019.

52. Stamatakis A. RAXML version 8: a tool for phylogenetic analysis and postanalysis of large phylogenies. Bioinformatics. 2014;30:1312-3.

\section{Publisher's Note}

Springer Nature remains neutral with regard to jurisdictional claims in published maps and institutional affiliations. 